Research Article

\title{
Decision Tree Model for Rockburst Prediction Based on Microseismic Monitoring
}

\author{
Hongbo Zhao $\mathbb{D}^{1},{ }^{1}$ Bingrui Chen, ${ }^{2}$ and Changxing $\mathrm{Zhu}^{3}$ \\ ${ }^{1}$ School of Civil and Architectural Engineering, Shandong University of Technology, Zibo, Shandong 255000, China \\ ${ }^{2}$ Institute of Rock and Soil Mechanics, Chinese Academy of Sciences, Wuhan, Hubei 430071, China \\ ${ }^{3}$ School of Civil Engineering, Henan Polytechnic University, Jiaozuo, Henan 454000, China \\ Correspondence should be addressed to Hongbo Zhao; bxhbzhao@hotmail.com
}

Received 13 May 2020; Revised 5 January 2021; Accepted 25 January 2021; Published 4 February 2021

Academic Editor: Emanuele Brunesi

Copyright ( $\odot 2021$ Hongbo Zhao et al. This is an open access article distributed under the Creative Commons Attribution License, which permits unrestricted use, distribution, and reproduction in any medium, provided the original work is properly cited.

Rockburst is an extremely complex dynamic instability phenomenon for rock underground excavation. It is difficult to predict and evaluate the rank level of rockburst in practice. Microseismic monitoring technology has been adopted to obtain microseismic events of microcrack in rock mass for rockburst. The possibility of rockburst can be reflected by microseismic monitoring data. In this study, a decision tree was used to extract the knowledge of rockburst from microseismic monitoring data. The predictive model of rockburst was built based on microseismic monitoring data using a decision tree algorithm. The predictive results were compared with the real rank of rockburst. The relationship between rockburst and microseismic feature data was investigated using the developed decision tree model. The results show that the decision tree can extract the rockburst feature from the microseismic monitoring data. The rockburst is predictable based on microseismic monitoring data. The decision tree provides a feasible and promising approach to predict and evaluate rockburst.

\section{Introduction}

Rockburst is a kind of sudden dynamic failure and instability phenomenon of rock mass which usually causes injury to workers and economic losses for rock underground excavation such as mining engineering and tunnel engineering. In China, rockburst is becoming a more and more serious problem for rock engineering with increasing depth of mining and underground rock excavation [1]. In 1966, Cook et al. proposed and applied rock mechanics to study and predict rockburst in mining [2]. Since then, various models have been developed to predict or evaluate the rockburst based on rock mechanics theory in the past decades. Based on rock mechanics, various predictive methods of rockburst have been developed and proposed by the empirical method, experimental method, analytical method, numerical method, and intelligent method [3-21]. Recently, Zhou et al. [22] and Sajjad et al. [23, 24] reviewed the state-of-the-art of theory, predictive method, and data preprocessing of rockburst in brief and classified the various methods into the empirical method, experimental method, analytical method, intelligent method, and numerical method [22-24]. But, it is difficult to predict and evaluate rockburst accurately based on the above studies due to the unclear mechanism of rockburst and uncertainty and complexity of rock mass materials. Rockburst prediction remains a universal issue for rock underground excavation till now.

Some researchers considered rockburst as microseismic events that result in severe damage to rock mass structure with sudden or intensive acoustic emissions [25-27]. Microseismic monitoring technology has been widely used in rock mechanics and provides a feasible way to predict or prewarn rockburst [28-31]. Feng et al. proposed a neural network prediction model based on the microseismic monitoring information [1]. Ma et al. studied the seismic source, seismogenic period, and scale effect of rockburst and believed that rockburst can be predicted based on the relationship between rock heterogeneity and acoustic emission sequence [32]. Xu et al. applied the ideal-point method to predict rockburst based on the information theory [33]. Currently, microseismic monitoring has been widely used to predict, evaluate, and prewarn the rockburst in rock 
underground excavation. Microseismic monitoring also provides a large amount of data about rockburst.

With the development of machine learning, it provides a powerful tool to reveal the mechanism behind data [34, 35]. The decision tree is a supervised machine learning algorithm and is commonly used in various engineering fields [36]. Microseismic monitoring provides a deluge of microseismic data about rockburst. How to extract the rockburst information and knowledge from data is an important challenge to predict or evaluate rockburst. The combination of microseismic monitoring data, machine learning, and rockburst theory offers an exciting new opportunity for expanding our knowledge about rockburst. In this study, a decision tree was adopted to build the predictive model of rockburst through the combing of microseismic monitoring data.

\section{Decision Tree}

A decision tree is a decision support tool that uses a tree-like model of decisions and their possible consequences, including chance event outcomes, resource costs, and utility. Decision tree learning is a method commonly used in machine learning [36]. The goal is to create a model that predicts the value of a target variable based on several input variables. The target variable of classification trees can take a discrete set of values, and the target variable of regression trees can take continuous values (typically real numbers). Each interior node corresponds to one of the input variables; there are edges to children for each of the possible values of that input variable. Each leaf represents a value of the target variable given the values of the input variables represented by the path from the root to the leaf (Figure 1). There are many specific decision tree algorithms such as Iterative Dichotomiser 3 (ID3), Classification and Regression Tree (CART), and CHi-squared Automatic Interaction Detector (CHAID) [37, 38].

In the decision trees, primary splitters (i.e., input variables that appear in the upper levels of the tree) that are directly connected with leaf nodes are considered the most influential factors in determining the value of the target attribute. In this study, the CART algorithm is adopted to build the decision tree model for rockburst prediction. The CART is a classical algorithm that has been commonly utilized to build a decision tree. To develop a CART model, recursive binary splitting is used. To the classification decision tree, the Gini splitting rule was adopted in this study. The strategy of Gini permutations/measurements was also used to determine the importance of each feature in the samples [39].

Consider that the $n_{\mathrm{k}}$ samples' fraction from the $(k=0,1)$ category out of all the samples at the node $\tau$ is expressed as follows:

$$
p_{k}=\frac{n_{k}}{n},
$$

where $p$ refers to the probability of having a specific data class in a branch of the decision tree model (node $\tau$ ). The

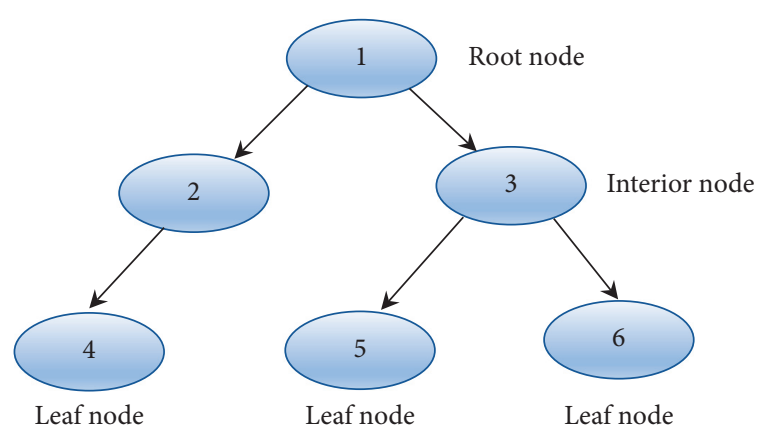

Figure 1: A simple example of the decision tree.

following equation presents the mathematical expression for the Gini impurity $i_{\tau}$ :

$$
i_{\tau}=1-\sum_{k} p_{k}^{2}
$$

If the node has only one single class, the equation output becomes zero, that is, the best value for the impurity. For a two-class problem (class 0 and class 1$), i_{\tau}$ is calculated as follows:

$$
i_{\tau}=1-p_{1}^{2}-p_{0}^{2} .
$$

As the samples are separated and sent to subnodes $\tau_{1}$ and $\tau_{2}$, the Gini impurity changes. To define the reduction amount of $i_{\tau}$, as a result of separating and sending the samples to subnodes $\tau_{1}$ and $\tau_{2}$ by a threshold $t_{\theta}$ on feature $\theta$, the following expression can be used:

$$
\Delta i_{\tau}=i_{\tau}-p_{l} i_{\tau 1}-p_{r} i_{\tau 2} .
$$

Depending on the applied setting (when creating a tree), the ideal strategy is to make enough branches until each branch has a Gini impurity of zero.

Conducting a proper/systematic search over all the available features at the node, the pair $\left\{\theta, t_{\theta}\right\}$ that leads to a maximal $\Delta_{i}$ is obtained. After this stage, the algorithm records and accumulates a decrease in $i_{\tau}$ for all the nodes (individually for all features). To the decision tree, the Gini importance is an index and can be used to measure the heterogeneity of the node. In the CART algorithm, the Gini importance is calculated using the following expression [39]:

$$
I_{G}(\theta)=\sum_{t} \sum_{\tau} \Delta i_{\theta}(\tau, T),
$$

where $I_{G}(\theta)$ is the Gini importance and $T$ is the number of trees in the model. The Gini importance indicates how often a specific feature $\theta$ is employed for a split and how important its general discriminative value is for the classification analysis of the objective function.

To build the tree, the information gain of each possible first split would need to be calculated. The best first split is the one that provides the most information gain. This process is repeated for each impure node until the tree is 
complete. In this study, ski-learn, which is a minimalist Python library for the decision tree, was adopted to build a decision tree model for rockburst prediction.

\section{Decision Tree Model for Rockburst Prediction}

It is difficult to predict or evaluate rockburst due to its indistinct mechanism and complicated phenomenon. Though lots of predictive models have been developed in the past decades, there is not a progression for predicting rockburst successfully. With the development of data sciences and machine learning, they provide a good way to obtain knowledge about rockburst from data. Microseismic monitoring technology can provide lots of data about the rockburst phenomenon. Machine learning can extract knowledge and information from the data. In this study, a novel model of rockburst prediction was developed by combining the decision trees and microseismic data.

\subsection{Microseismic Monitoring and Microseismic Data about} Rockburst. The stress of the surrounding rock mass will be altered and redistributed with the underground structure excavation. The rock mass will release the stored elastic energy in the form of microseismic events with the appearance and development of microcracks when the redistributed stress is greater than the strength of the rock masses. This phenomenon is called acoustic emission [40]. Passive acoustic emission detection technology, which takes advantage of the local strain energy quickly released in engineering materials, is also known as the microseismic monitoring technology. Some researchers noticed an anomalous increase in microseismic events before the occurrence of rockburst. To date, microseismic monitoring technology has been an important tool to predict and avoid rockburst. The predictive method and model of rockburst have been developed and applied to rock underground excavation based on microseismic monitoring data [41-44]. In this study, a decision tree was adopted to predict rockburst by building the relationship between rockburst and microseismic information.

The occurrence of rockburst is related to microseismic monitoring information. To predict rockburst based on microseismic monitoring data, it is critical to reasonably determine the key parameters of microseismic data which can represent the rockburst. Feng et al. developed and proposed a predictive model based on microseismic monitoring using neural networks [1]. In this study, the number of microseismic events, microseismic energy, microseismic apparent volume, and development time were selected to predict rockburst. Various studies of rockburst rank have been conducted in the last decades. Russnes proposed and classified the rockburst intensity into four ranks, i.e., none, weak, moderate, and severe [45]. Brauner classified the rockburst into three ranks based on the intensity of destruction to the surrounding rock mass [46]. Tan classified the rockburst into four ranks based on lots of laboratory tests and field investigations [47]. Cai et al. developed the four ranks of rockburst to evaluate the rockburst liability [48]. The four ranks method of rockburst classification has been widely used in mining, tunnel, and other rock engineering. So, the four ranks of rockburst were adopted in this study. The input of the decision tree was the number of microseismic events, microseismic energy, microseismic apparent volume, and development time, respectively. The output is the ranks of rockburst, i.e., no rockburst, moderate rockburst, strong rockburst, and violent rockburst. Numbers 1, 2, 3, and 4 were adopted to represent the different ranks of rockburst in the decision tree model (1-no rockburst, 2-moderate rockburst, 3strong rockburst, and 4-violent rockburst).

3.2. Datasets. Learning samples are critical to the model effect of the decision tree. In the literature, lots of researchers collected plenty of case histories and laboratory tests' results and evaluated the potential of rockburst using different predictive models such as empirical models, numerical models, and intelligent models. In this study, the datasets were collected from the literature based on the previous works [1]. The datasets consist of 173 samples which have four influencing factors and a corresponding rank (label) of rockburst. The dataset was divided into 153 training samples and 20 test samples. Figures 2 and 3 show the relationship between rockburst rank and microseismic feature parameters. It is obvious that their relationships are very complex, and it is impossible to be characterized using the traditional mathematical model. Therefore, the decision tree model was adopted to evaluate the rockburst rank based on microseismic data. Table 1 lists the testing samples.

3.3. Rockburst Prediction. To verify and illustrate the rockburst predictive model based on a decision tree, the above samples were used to train a decision tree model using the CART algorithm. The samples were divided into learning samples and testing samples. The number of learning and testing samples were 153 and 20, respectively. The performance of the decision tree was evaluated, and the predicted results were compared with the real rank of rockburst. The results show that the decision tree model can be used to predict rockburst. It also presented the microseismic monitoring parameter's affection for rockburst. It proved that the decision tree provides a good tool to predict and evaluate rockburst based on microseismic monitoring technology with the supplementation of microseismic data.

3.4. Decision Tree Model for Rockburst Prediction. The structure of the decision tree is shown in Figure 4 based on the training samples. 20 test samples were used to verify the decision tree model. Table 1 lists the predicted results and their comparison with the real rank of rockburst. The predicted rank of 18 samples is in excellent agreement with the real rank, and 2 samples (nos. 4 and 14) are not classified correctly. The error ratio is about $10 \%$. To further verify the decision tree model, it was used to determine the rockburst rank of eight real case histories [1]. The results are listed in Table 2 . Two case histories were not predicted correctly. The 

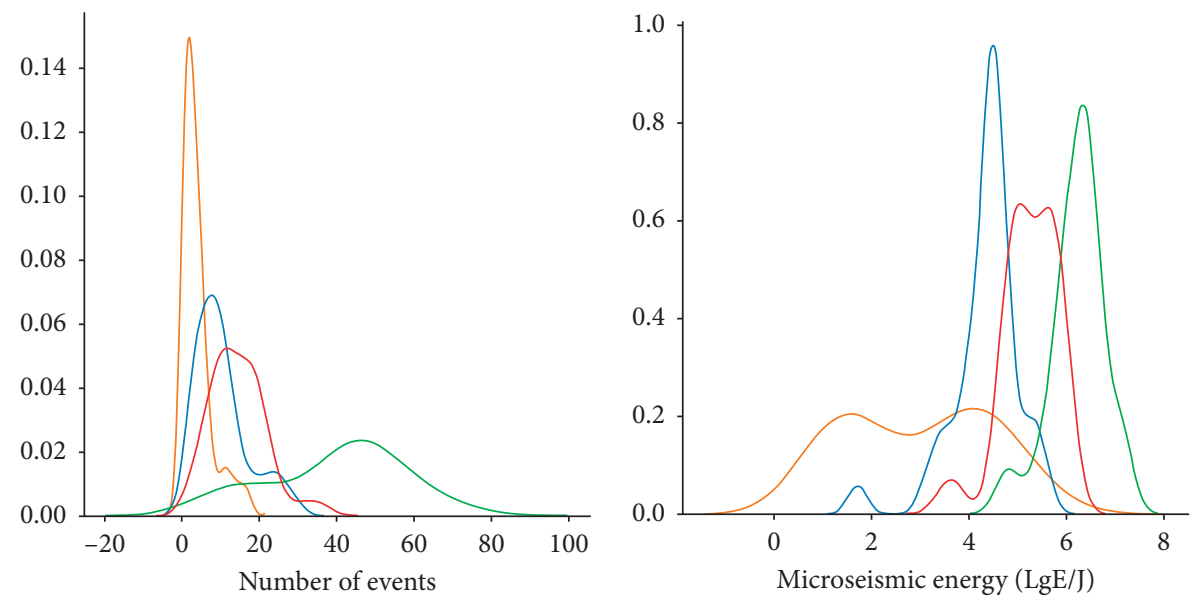

Rockburst rank

— Moderate rockburst

— No rockburst

— Violent rockburst

— Strong rockburst

(a)

Rockburst rank

— Moderate rockburst

_ No rockburst

— Violent rockburst

__ Strong rockburst

(b)
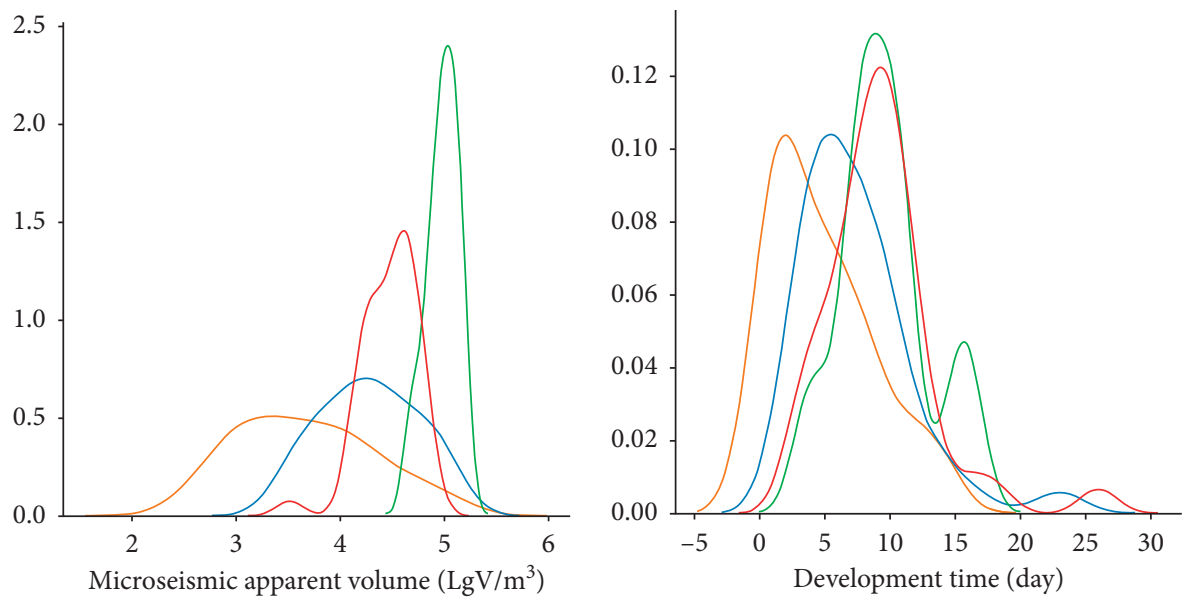

Rockburst rank

— Moderate rockburst

_ No rockburst

- Violent rockburst

_ Strong rockburst

(c)

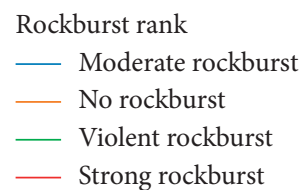

(d)

FIGURE 2: The relationship between rockburst rank and microseismic parameters.

error in prediction occurred at the neighboring rank for the nos. 4 and 14 test samples and nos. 3 and 7 case histories. As we know, the mechanism of rockburst is not clearly understood till now. The relationship between rockburst and microseismic data is also not clear and remains uncertain. It is difficult to distinguish the rank of rockburst which falls in between two neighboring ranks. With the increasing of microseismic monitoring data, the prediction precision can be improved. Thus, the decision tree has the capacity of predicting rockburst based on microseismic monitoring information. The proposed method provides a good way to evaluate the rockburst rank.
3.5. Important Feature in Microseismic Data. Due to the unclear mechanism of rockburst, it is difficult to select the proper microseismic parameters and present the relationship between the rockburst rank and the selected microseismic parameters. Based on the decision tree model of rockburst, Shapley additive explanations (SHAP) was used to evaluate the important feature of microseismic data. The important feature order is microseismic energy, number of microseismic events, microseismic apparent volume, and development time, respectively (Figure 5). Figure 6 shows the impact of each sample and its input on the rockburst rank. The proposed 

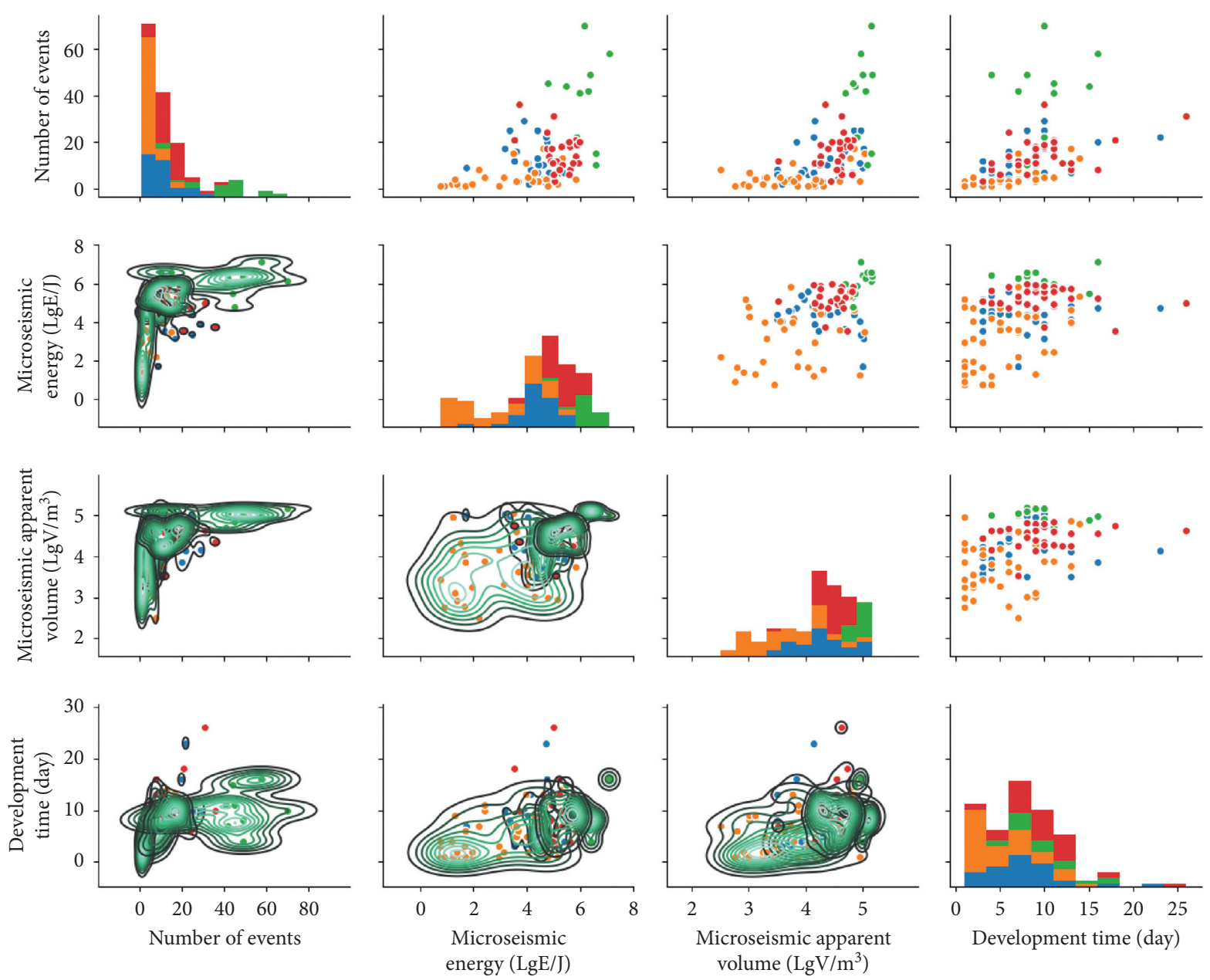

Rockburst rank

- Moderate rockburst

- Violent rockburst

- No rockburst

- Strong rockburst

Figure 3: Bivariate relationship of microseismic parameters with the rockburst rank.

Table 1: Predicted results of test samples using the decision tree.

\begin{tabular}{|c|c|c|c|c|c|c|}
\hline \multirow{2}{*}{ No. } & \multirow{2}{*}{ Number of events } & \multirow{2}{*}{ Microseismic energy (LgE/J) } & \multirow{2}{*}{$\begin{array}{l}\text { Microseismic apparent } \\
\text { volume }\left(\mathrm{LgV} / \mathrm{m}^{3}\right)\end{array}$} & \multirow{2}{*}{ Development time (day) } & \multicolumn{2}{|c|}{ Rockburst rank } \\
\hline & & & & & Real & Prediction \\
\hline 1 & 17 & 3.172 & 5.015 & 10 & 2 & 2 \\
\hline 2 & 2 & 1.94 & 3.25 & 1 & 1 & 1 \\
\hline 3 & 42 & 6.284 & 5.05 & 7 & 4 & 4 \\
\hline 4 & 21 & 5.848 & 4.834 & 11 & 3 & 4 \\
\hline 5 & 6 & 5.561 & 4.043 & 6 & 2 & 2 \\
\hline 6 & 22 & 5.859 & 4.895 & 10 & 4 & 4 \\
\hline 7 & 5 & 2.435 & 3.878 & 10 & 1 & 1 \\
\hline 8 & 7 & 4.381 & 4.132 & 4 & 2 & 2 \\
\hline 9 & 13 & 4.408 & 4.428 & 6 & 2 & 2 \\
\hline 10 & 44 & 5.459 & 4.865 & 15 & 4 & 4 \\
\hline 11 & 8 & 5.204 & 3.977 & 3 & 2 & 2 \\
\hline 12 & 14 & 5.841 & 4.622 & 6 & 3 & 3 \\
\hline 13 & 17 & 4.754 & 4.397 & 9 & 3 & 3 \\
\hline 14 & 15 & 3.486 & 5.03 & 7 & 1 & 2 \\
\hline 15 & 18 & 5.295 & 4.703 & 10 & 3 & 3 \\
\hline 16 & 10 & 5.322 & 4.238 & 7 & 3 & 3 \\
\hline 17 & 49 & 6.419 & 4.995 & 4 & 4 & 4 \\
\hline 18 & 14 & 4.818 & 4.266 & 11 & 3 & 3 \\
\hline 19 & 4 & 5.82 & 3.728 & 7 & 1 & 1 \\
\hline 20 & 24 & 4.748 & 4.66 & 6 & 3 & 3 \\
\hline
\end{tabular}




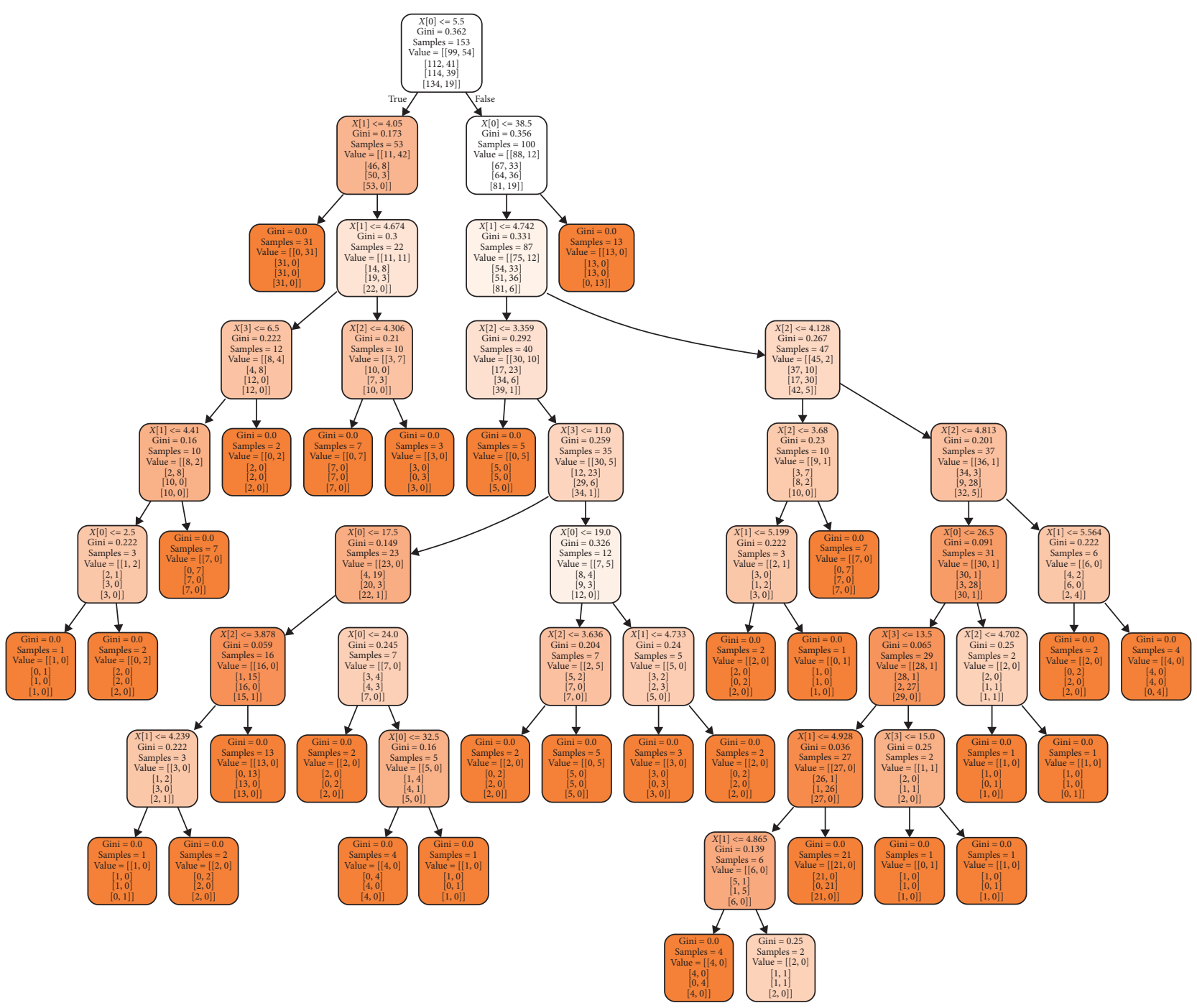

Figure 4: Structure of the decision tree model.

Table 2: Predictive results of eight case histories.

\begin{tabular}{|c|c|c|c|c|c|c|}
\hline \multirow{2}{*}{ No. } & \multirow{2}{*}{ Number of events } & \multirow{2}{*}{ Microseismic energy $(\mathrm{LgE} / \mathrm{J})$} & \multirow{2}{*}{ Microseismic apparent volume $\left(\mathrm{LgV} / \mathrm{m}^{3}\right)$} & \multirow{2}{*}{ Development time (day) } & \multicolumn{2}{|c|}{ Rockburst rank } \\
\hline & & & & & Real & Prediction \\
\hline 1 & 29 & 5.513 & 4.777 & 5 & 4 & 4 \\
\hline 2 & 15 & 6.587 & 5.152 & 9 & 4 & 4 \\
\hline 3 & 10 & 4.886 & 4.105 & 6 & 3 & 2 \\
\hline 4 & 17 & 4.944 & 4.598 & 10 & 3 & 3 \\
\hline 5 & 19 & 5.865 & 4.263 & 7 & 3 & 3 \\
\hline 6 & 7 & 4.834 & 4.116 & 13 & 2 & 2 \\
\hline 7 & 5 & 5.17 & 4.594 & 6 & 2 & 3 \\
\hline 8 & 1 & 1.67 & 4.033 & 1 & 1 & 1 \\
\hline
\end{tabular}

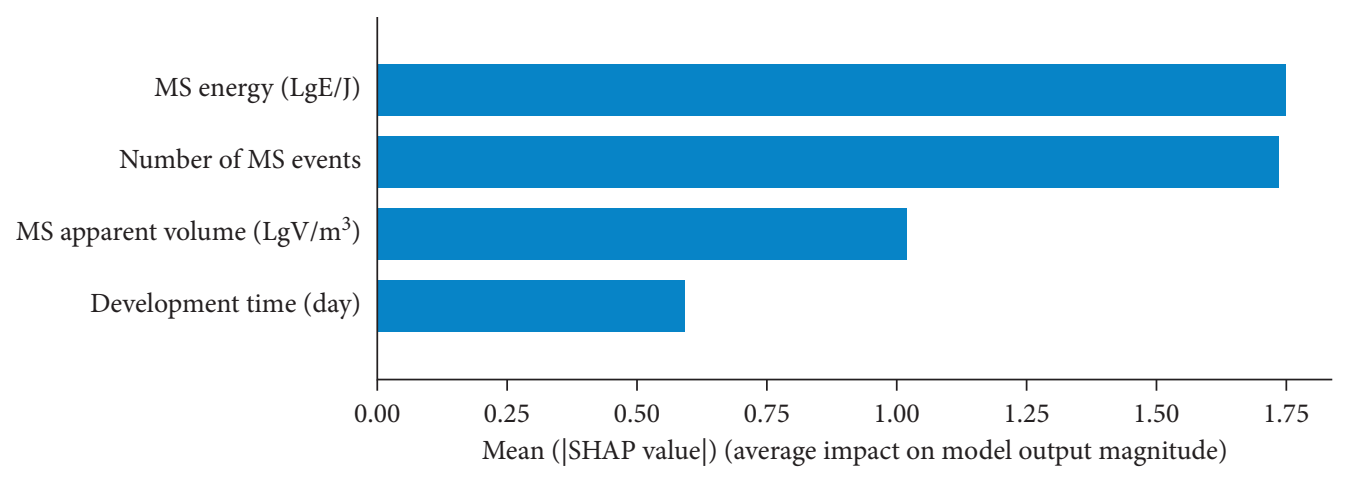

FIGURE 5: The important feature order of microseismic parameters based on SHAP. 


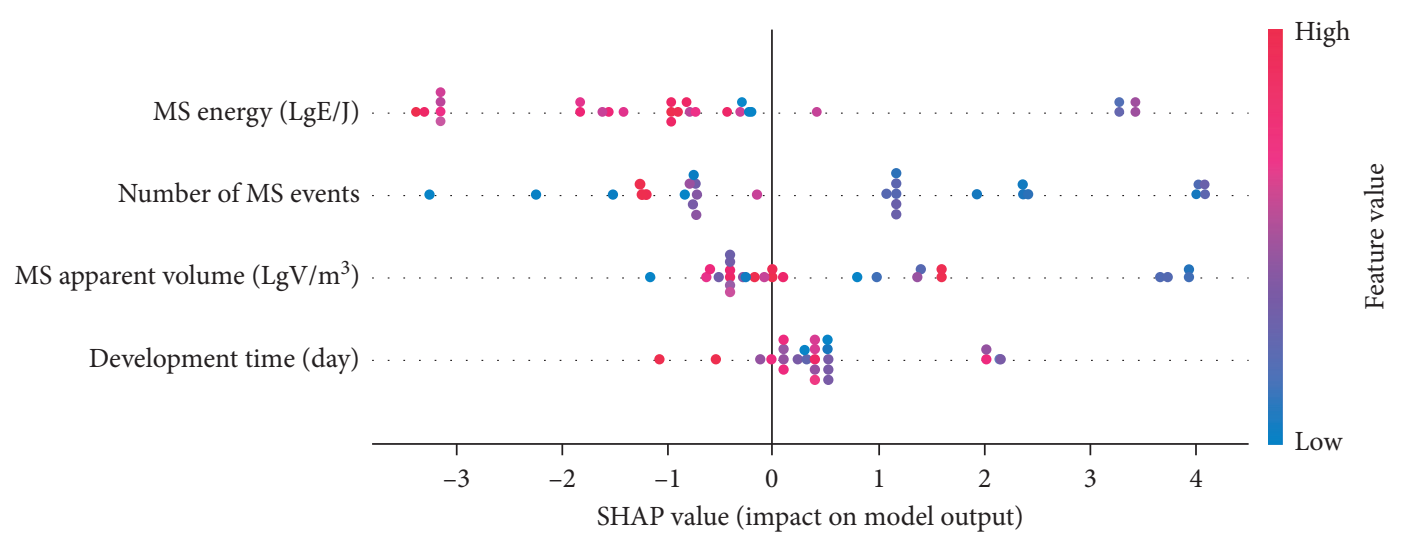

FIGURE 6: Impact on rockburst of different microseismic parameters based on SHAP.

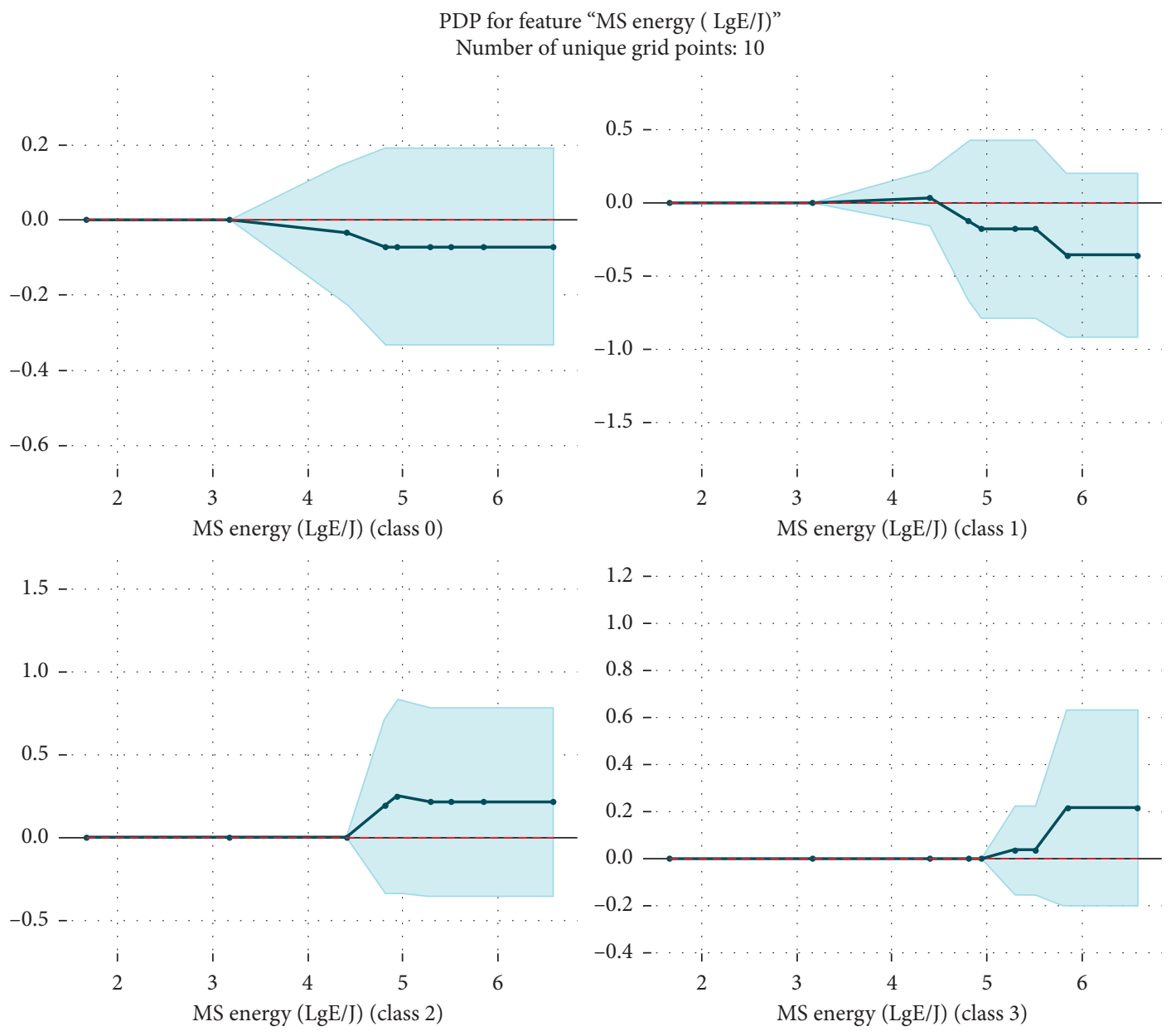

FIGURE 7: Impact of MS energy on rockburst.

model shows that microseismic energy and the number of microseismic events have a higher impact on rockburst. Figures 7 and 8 show the impact of microseismic energy and the number of microseismic events on the rank of rockburst, respectively. It shows that the rank level of rockburst is higher with the higher microseismic energy and the larger number of microseismic events. It is well in agreement with the rockburst theory. It shows that the knowledge extracted from data meets the rockburst theory. It proved that it is feasible to build a rockburst predictive model based on microseismic monitoring data. And, it also proved that the decision tree captures well the relationship between rockburst rank and microseismic feature parameters. 
PDP for feature "number of MS events"

Number of unique grid points: 10
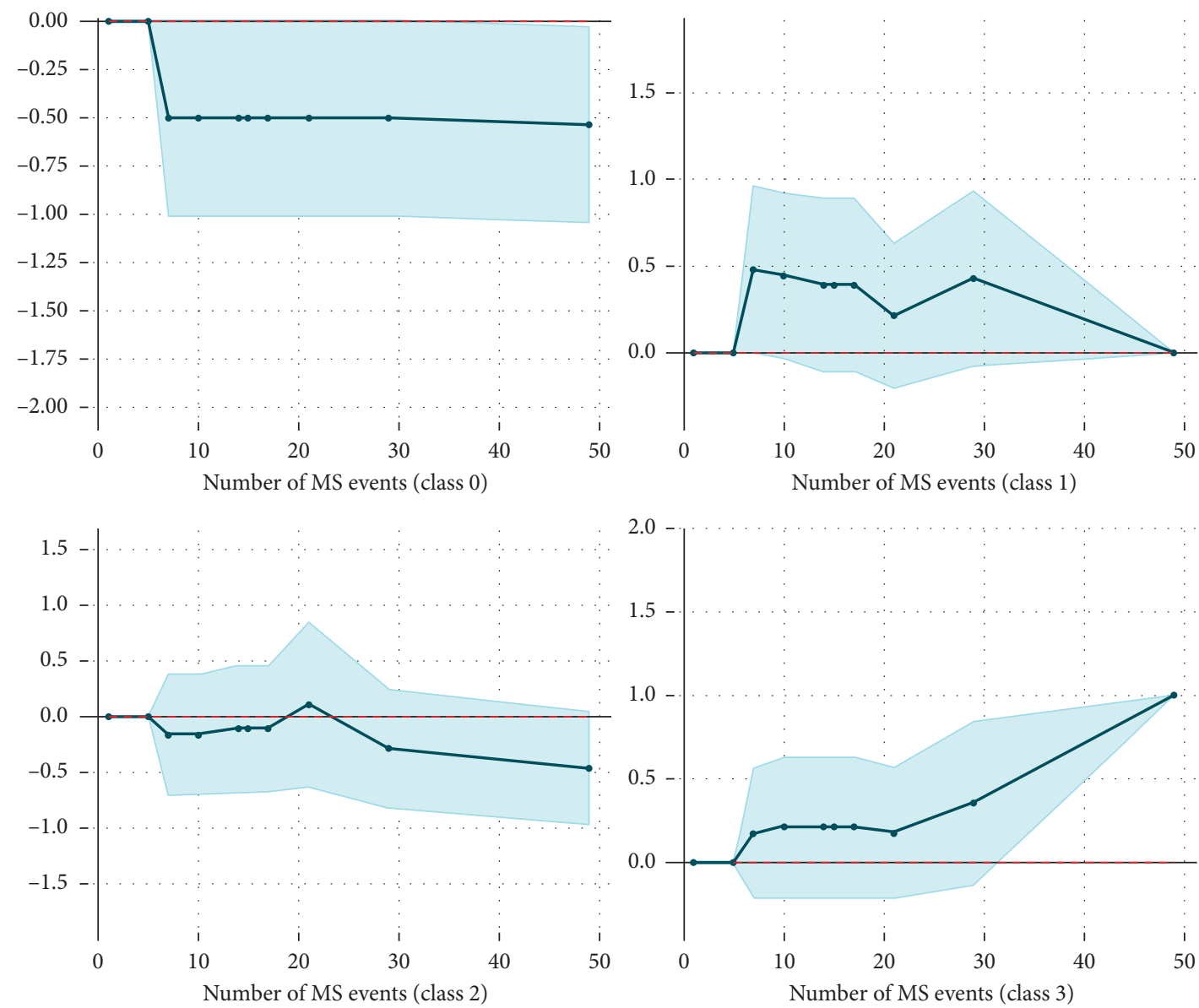

FIGURE 8: Impact of the number of MS events on rockburst.
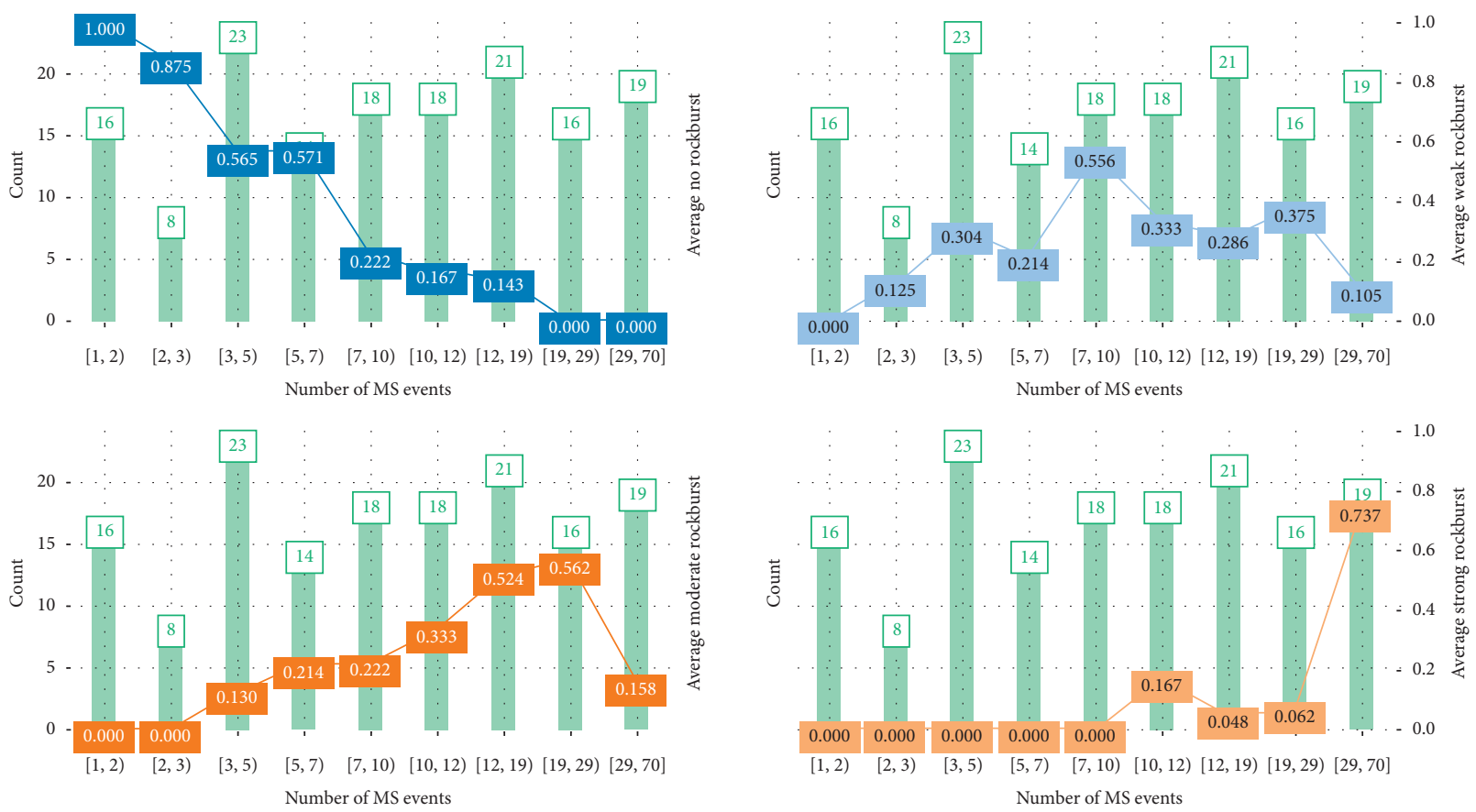

(a)

FIgURe 9: Continued. 

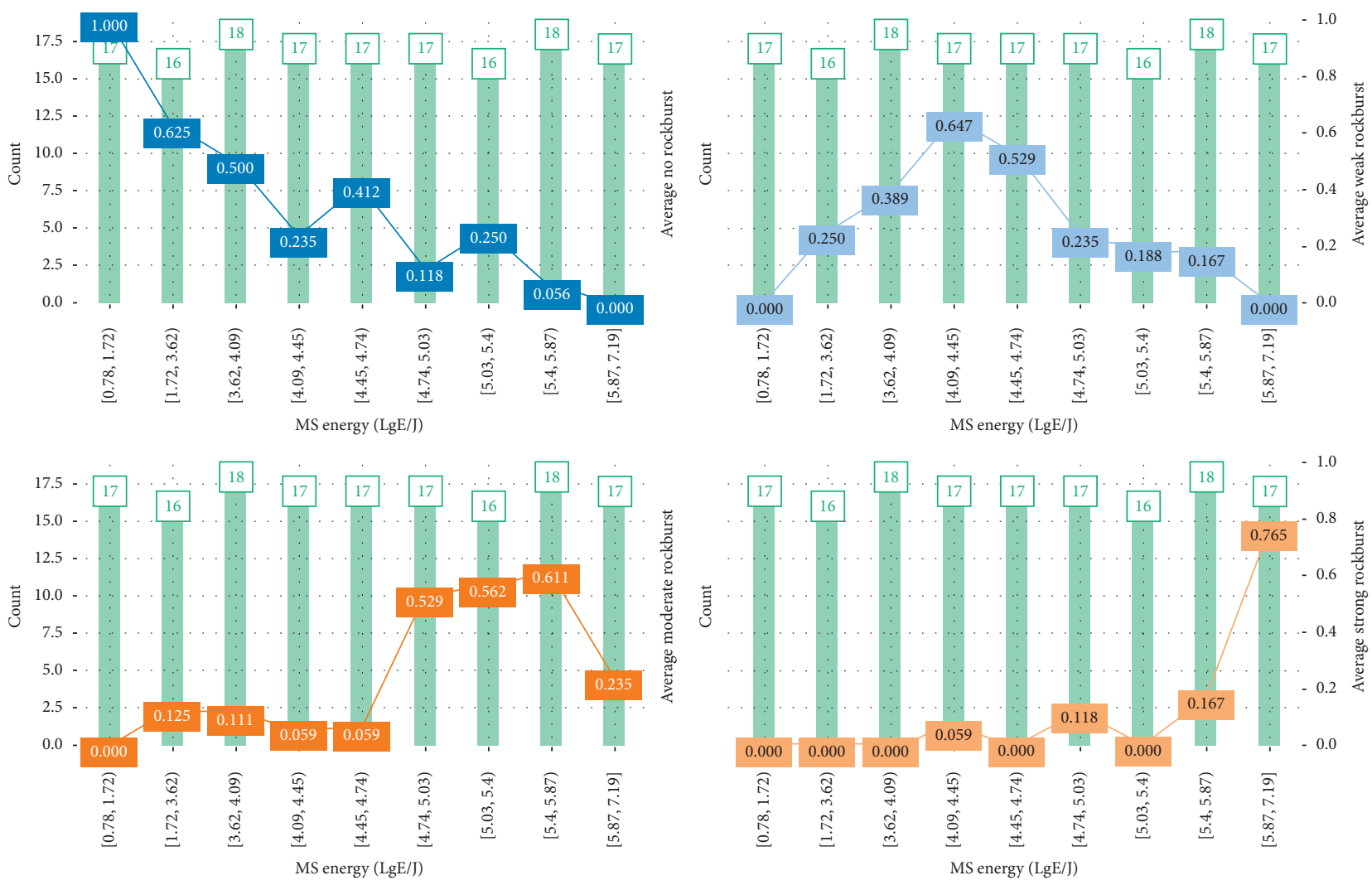

(b)
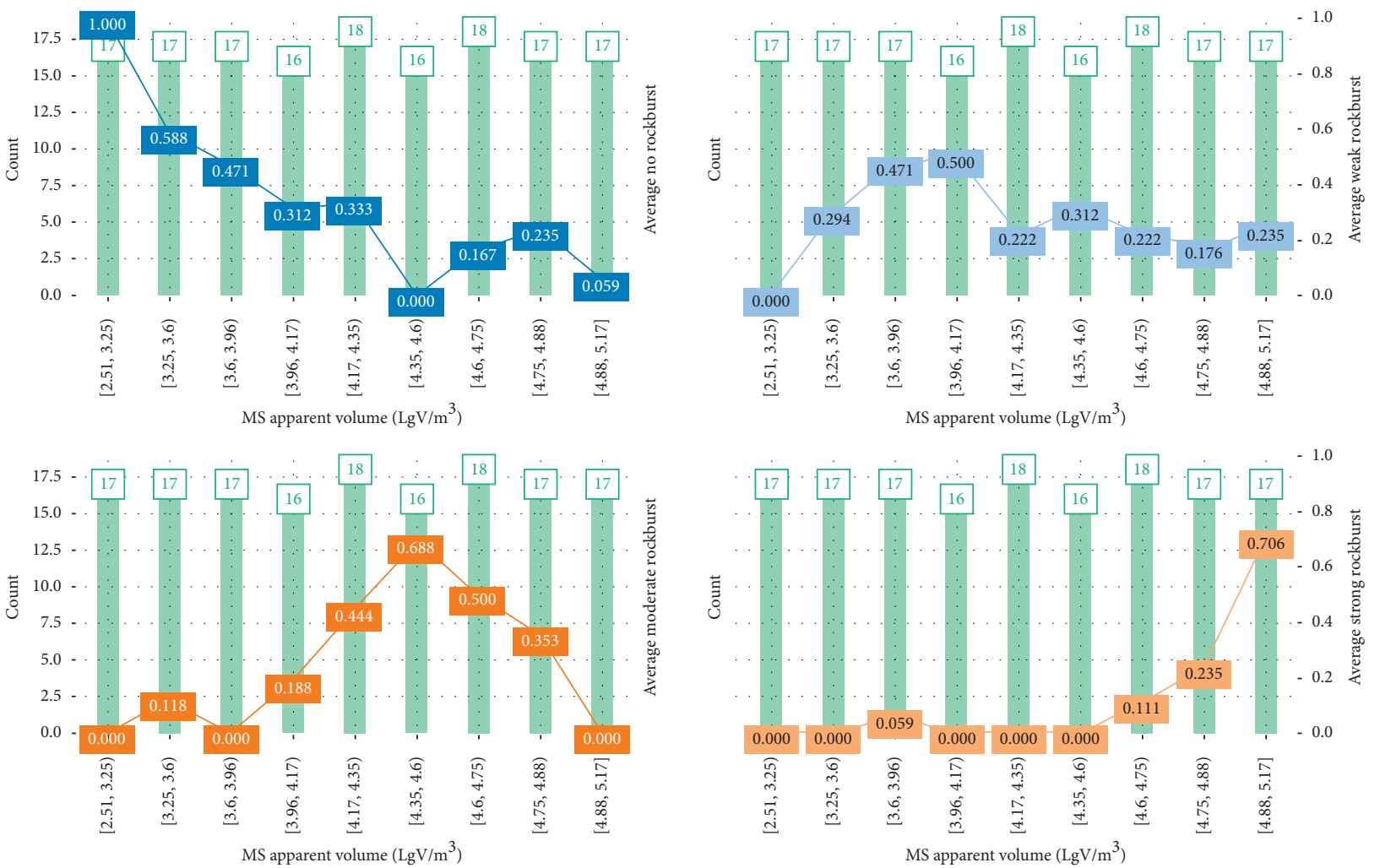

(c)

FIgURE 9: Continued. 

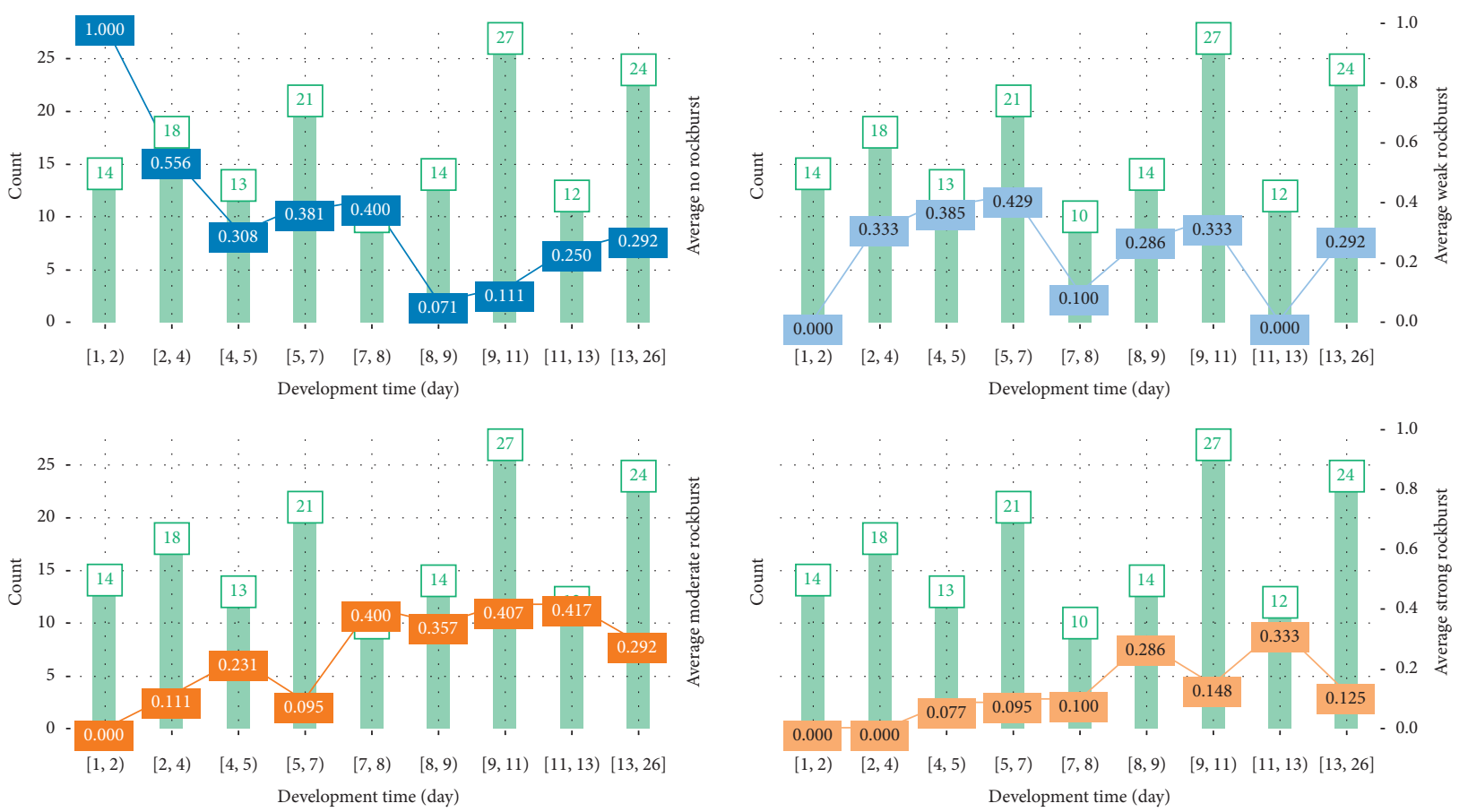

(d)

FIGURE 9: Impact of MS parameters on rockburst. (a) Number of MS events. (b) MS energy. (c) MS apparent volume. (d) Development time.

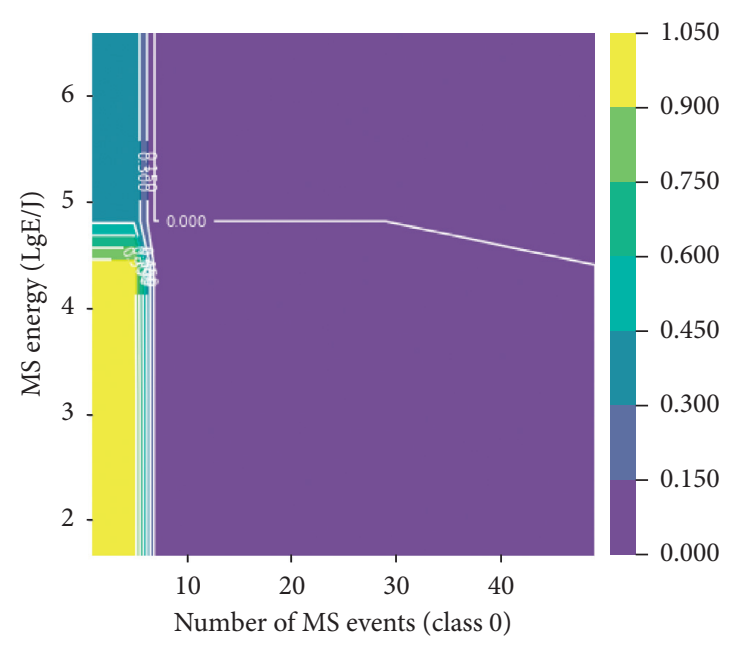

(a)

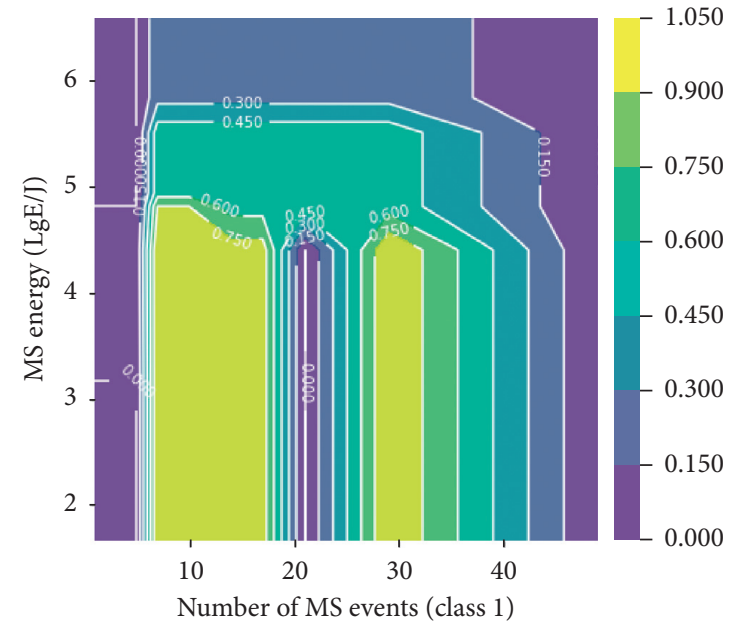

(b)

FIgURE 10: Continued. 


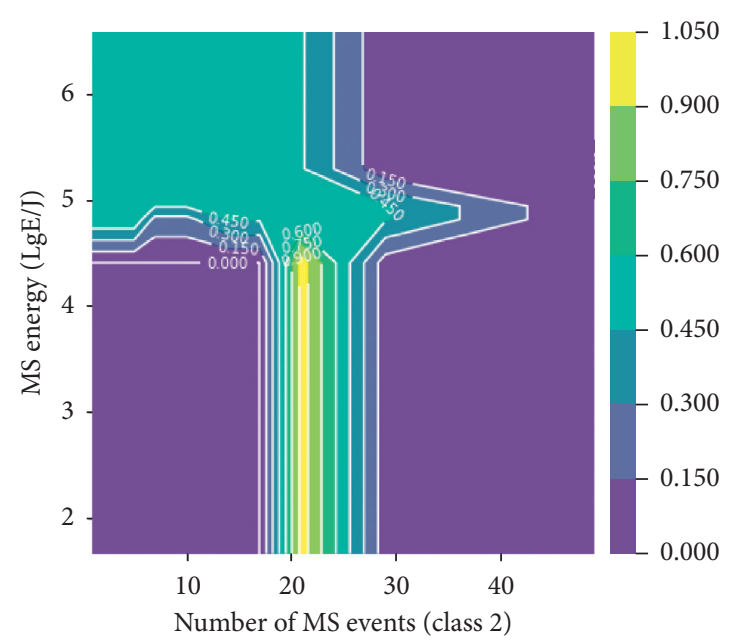

(c)

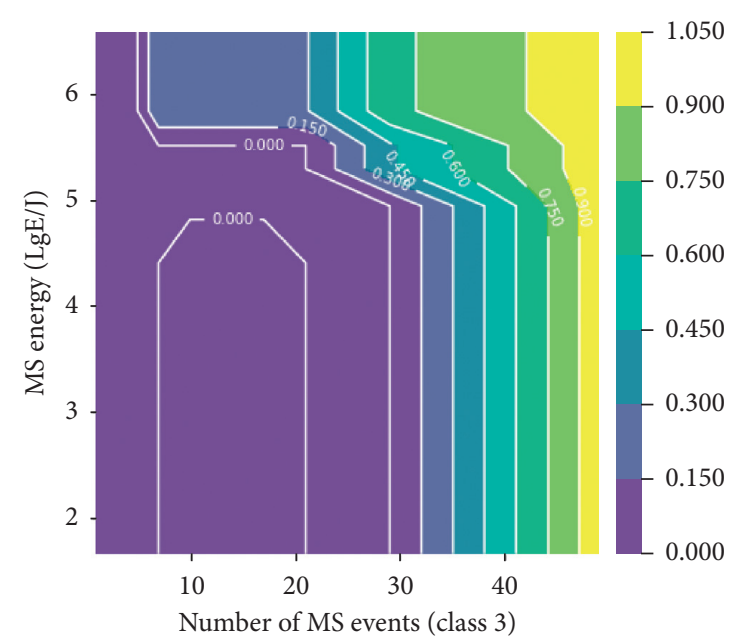

(d)

FIGURE 10: Interactive impact of the energy and events' number of MS on rockburst.

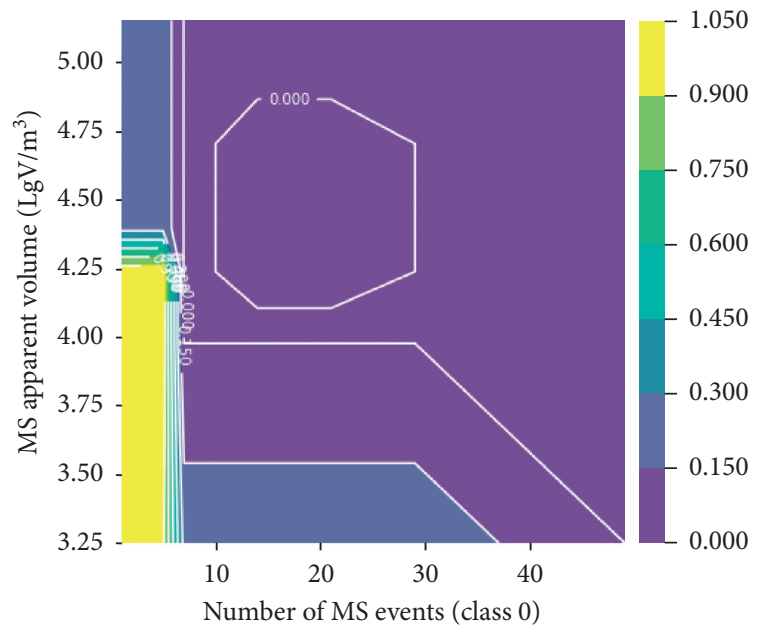

(a)

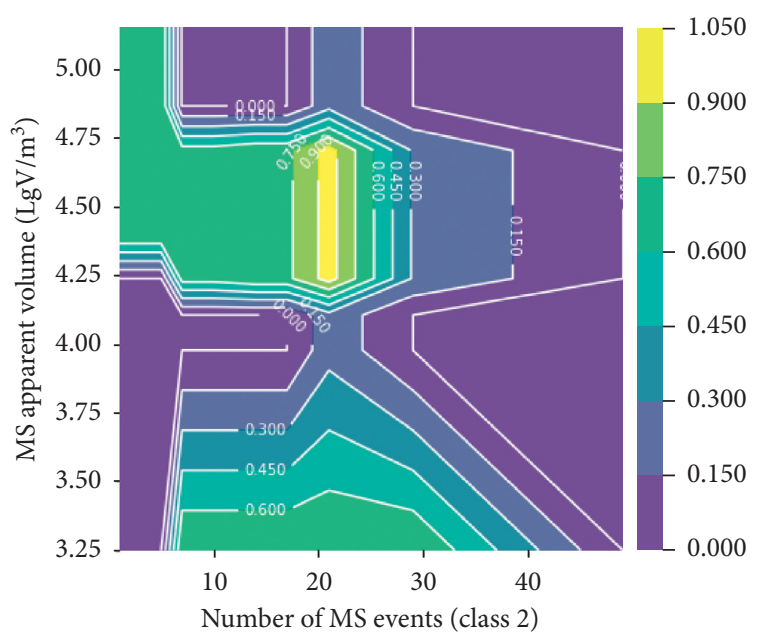

(c)

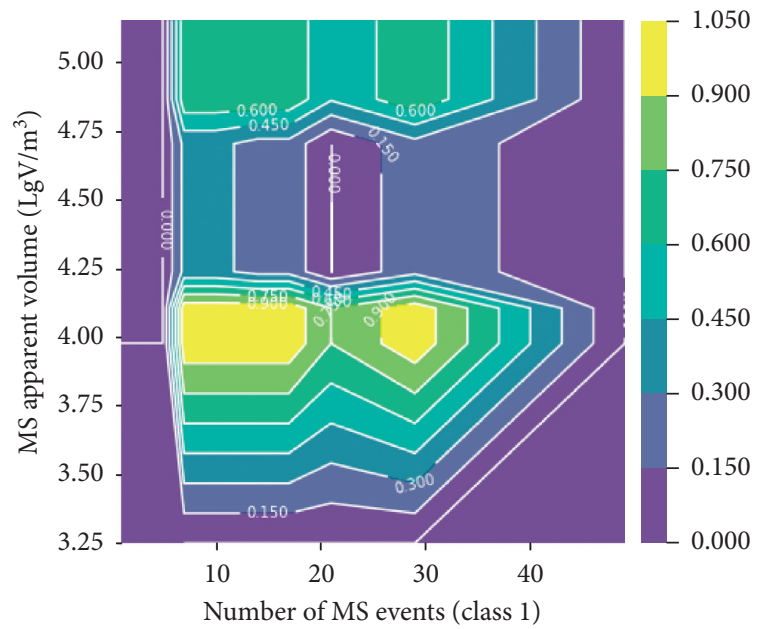

(b)

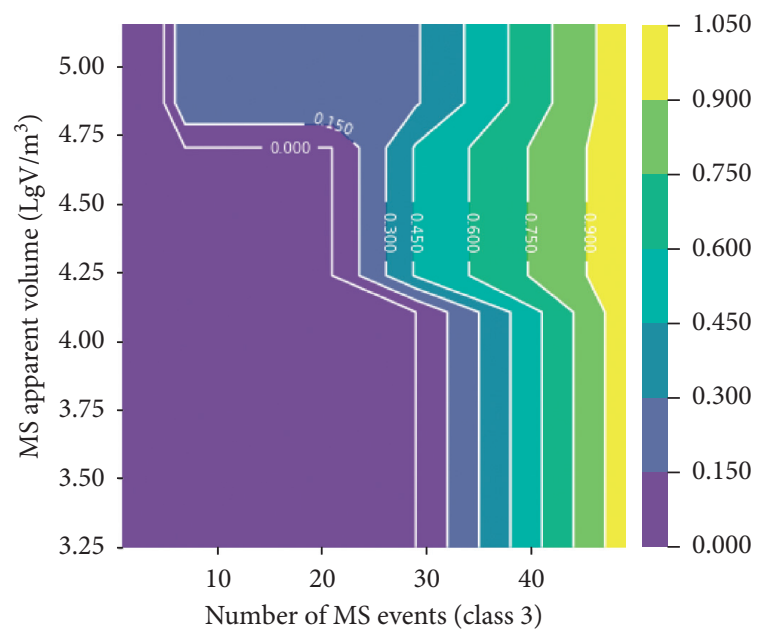

(d)

FIGURE 11: Interactive impact of the energy and apparent volume of MS on rockburst. 


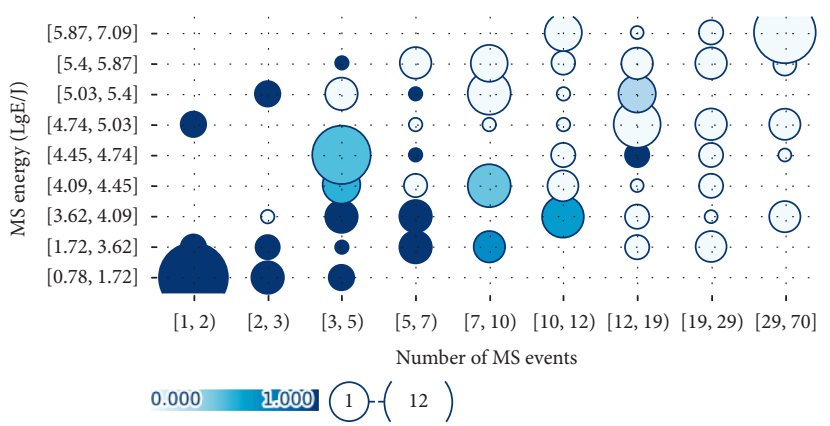

(a)

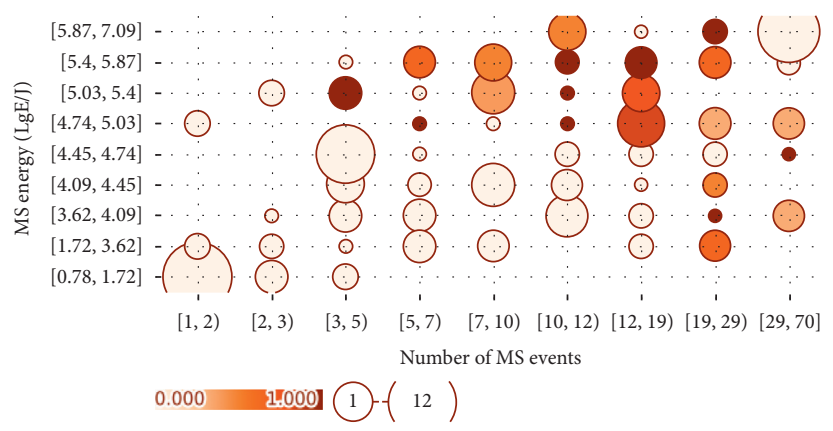

(c)

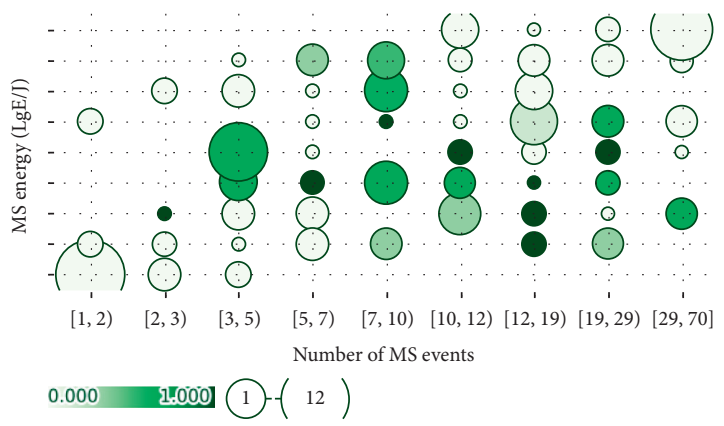

(b)

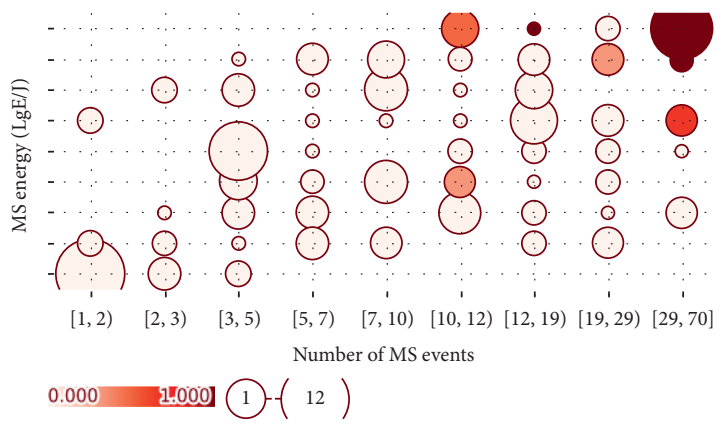

(d)

FIgURE 12: Interactive impact of the energy and events' number of MS on rockburst. (a) Avereage no rockburst. (b) Avereage weak rockburst. (c) Avereage moderate rockburst. (d) Avereage strong rockburst.

3.6. Impact of the Single Microseismic Parameters on Rockburst. The microseismic parameters have an impact on the rank level of rockburst. Different values of microseismic parameters reflect the different potential of rockburst. Figure 9 shows the relationship between the microseismic parameters and the rank level of rockburst. The rank level of rockburst increases from no rockburst to strong rockburst with the increasing microseismic events' number (Figure 9(a)). Similar findings were observed for microsismic energy and microseismic apparent volume. No obvious correlation was found between the development time and the rockburst rank. But to the development time, there are no distinct relations to rockburst. It also implied that development time is not significant to evaluate rockburst rank and is stated in Section 3.5.

3.7. Interactive Impact of the Microseismic Parameters on Rockburst. The mechanism of rockburst is unclear, and the relationship between rockburst and microseismic parameters is very complex and uncertain. The interaction between microseismic parameters was evaluated based on the decision tree model. Figure 10 shows the interactive impact of microseismic energy and the number of events on rockburst. It showed that the value of energy and the number of events of microseismic are smaller for the scenario of no rockburst (class 0). But, the impact on rockburst is very complex, nonlinear, and uncertain for rockburst (class 1-2). The interactive impact of microseismic energy and microseismic apparent volume on rockburst are similar to the above case (Figure 11). With the increase of microseismic energy and microseismic events' number, the potential of rockburst will increase, but their relationship is nonlinear and complex (Figure 12). It proved the rockburst phenomenon is very complex, and it is difficult to propose a predictive model based on traditional methods but the decision tree provides a good way to evaluate it.

\section{Conclusions}

Rockburst is an extremely serious geological disaster to the rock underground excavation. It is difficult to predict rockburst using traditional methods based on rock mechanics. In this study, a decision tree was adopted to predict and evaluate the rank level of rockburst based on microseismic monitoring data. The relationship between rockburst and microseismic feature parameters was represented using the decision tree. The proposed method was applied to 20 test samples and eight case histories. The results proved that the relationship between the rockburst and the microseismic data is complex, uncertain, and nonlinear. It also showed that the decision tree model is a reasonable and feasible way to predict rockburst based on microseismic monitoring technology. It provides a scientific and rational approach to evaluate the rank level of rockburst for rock underground excavation. The following conclusions can be drawn:

(1) Rockburst is a complex dynamic instability phenomenon of the rock mass. It is difficult to predict, evaluate rockburst, and understand the mechanism of rockburst only based on rock mechanics. 
(2) Microseismic monitoring technology provides a good way to understand rockburst and its mechanism. Rockburst is predictable through understanding the relationship between microcrack in the rock mass and microseismic data feature.

(3) With the development of data science and machine learning technique, the decision tree model provides a good way to utilize microseismic monitoring data to extract knowledge about rockburst. The decision tree model can improve our understanding of the rockburst and evaluate effectively the rockburst rank despite the complexity.

(4) The decision tree model captured well the relationship between rockburst and microseismic features parameters. It has been proved more powerful and flexible than the traditional model based on rock mechanics. The decision tree offers exciting new opportunities for expanding our knowledge about rockburst with the microseismic monitoring technology.

(5) A decision tree is a kind of interpretable machine learning algorithm which can reveal the complicated and uncertain mechanism of the model based on data. The decision tree model provides a promising approach to understand rockburst through learning from microseismic monitoring information.

\section{Data Availability}

All data and models generated or used during the study are available upon request from the corresponding author.

\section{Conflicts of Interest}

The authors declare that there are no conflicts of interest regarding the publication of this paper.

\section{Acknowledgments}

This work was supported by the National Natural Science Foundation of China (Grant no. 51874119).

\section{References}

[1] X. T. Feng, B. R. Chen, C. Q. Zhang, S. J. Li, and S. Y. Wu, Mechanism, Warning and Dynamical Control of Rockburst Evolution Process, Science Press, Beijing, China, 2013.

[2] N. G. W. Cook, E. Hoek, J. P. G. Pretorius, W. D. Ortlepp, and M. D. G. Salamon, "Rock mechanics applied to the study of rockbursts," South African Institute of Mining and Metallurgy, vol. 66, no. 3, pp. 435-538, 1966.

[3] N. Barton, R. Lien, and J. Lunde, "Engineering classification of rock masses for the design of tunnel support," Rock Mechanics Felsmechanik Mecanique des Roches, vol. 6, no. 4, pp. 189-236, 1974.

[4] C. H. Dowding and C.-A. Andersson, "Potential for rock bursting and slabbing in deep caverns," Engineering Geology, vol. 22, no. 3, pp. 265-279, 1986.
[5] J. P. Bardet, "Finite element analysis of rockburst as surface instability," Computers and Geotechnics, vol. 8, no. 3, pp. 177-193, 1989.

[6] W. Müller, "Numerical simulation of rock bursts," Mining Science and Technology, vol. 12, no. 1, pp. 27-42, 1991.

[7] W. D. Ortlepp and T. R. Stacey, "Rockburst mechanisms in tunnels and shafts," Tunnelling and Underground Space Technology, vol. 9, no. 1, pp. 59-65, 1994.

[8] P. K. Kaiser, D. D. Tannant, D. R. Mccreath, and R. Jesenak, "Rockburst damage assessment procedure," in Rock Support in Mining and Underground Construction, P. K. Kaiser and D. R. McCreath, Eds., pp. 639-647, Balkema, Rotterdam, Netherlands, 1992.

[9] H. B. Zhao, "Classification of rockburst using support vector machine," Rock and Soil Mechanics, vol. 26, no. 4, pp. 642644, 2005, in Chinese.

[10] S. Y. Wang, K. C. Lam, S. K. Au, C. A. Tang, W. C. Zhu, and T. H. Yang, "Analytical and numerical study on the pillar rockbursts mechanism," Rock Mechanics and Rock Engineering, vol. 39, no. 5, pp. 45-467, 2006.

[11] S. K. Sharan, "A finite element perturbation method for the prediction of rockburst," Computers and Structures, vol. 85, no. 17-18, pp. 1304-1309, 2007.

[12] G. S. Su, X. F. Zhang, and L. B. Yan, "Rockburst prediction method based on case reasoning pattern recognition," Journal of Mining and Safety Engineering, vol. 25, no. 1, pp. 63-67, 2008.

[13] M. C. He, J. L. Miao, and J. L. Feng, "Rock burst process of limestone and its acoustic emission characteristics under truetriaxial unloading conditions," International Journal of Rock Mechanics and Mining Sciences, vol. 47, no. 2, pp. 286-298, 2010.

[14] W. C. Zhu, Z. H. Li, L. Zhu, and C. A. Tang, "Numerical simulation on rockburst of underground opening triggered by dynamic disturbance," Tunnelling and Underground Space Technology, vol. 25, no. 5, pp. 587-599, 2010.

[15] Q. Jiang, X.-T. Feng, T.-B. Xiang, and G.-S. Su, "Rockburst characteristics and numerical simulation based on a new energy index: a case study of a tunnel at 2,500 $\mathrm{m}$ depth," Bulletin of Engineering Geology and the Environment, vol. 69, no. 3, pp. 381-388, 2010.

[16] B.-R. Chen, X.-T. Feng, Q.-P. Li, R.-Z. Luo, and S. Li, "Rock burst intensity classification based on the radiated energy with damage intensity at Jinping II hydropower station, China," Rock Mechanics and Rock Engineering, vol. 48, no. 1, pp. 289-303, 2013.

[17] J. Zhou, X. Li, and X. Shi, "Long-term prediction model of rockburst in underground openings using heuristic algorithms and support vector machines," Safety Science, vol. 50, no. 4, pp. 629-644, 2012.

[18] J. Zhou, X. B. Li, and H. S. Mitri, "Classification of rockburst in underground projects: comparison of ten supervised learning methods," Journal of Computing in Civil Engineering, vol. 30, no. 5, Article ID 04016003, 2016.

[19] N. Li, X. Feng, and R. Jimenez, "Predicting rock burst hazard with incomplete data using Bayesian networks," Tunnelling and Underground Space Technology, vol. 61, pp. 61-70, 2017.

[20] Y. Y. Pu, B. A. Derek, and L. Bob, "Rockburst prediction in kimberlite using decision tree with incomplete tree," Journal of Sustainable Mining, vol. 17, no. 3, pp. 158-165, 2018.

[21] H. Zhao and B. Chen, "Data-driven model for rockburst prediction," Mathematical Problem in Engineering, vol. 2020, Article ID 5735496, 14 pages, 2020. 
[22] J. Zhou, X. Li, and H. S. Mitri, "Evaluation method of rockburst: state-of-the-art literature review," Tunnelling and Underground Space Technology, vol. 81, pp. 632-659, 2018.

[23] A. Sajjad, S. Kourosh, and H. M. Sayyed, "Developing intelligent classification models for rockburst prediction after recognizing significant predictor variables, section 1: literature review and data preprocessing procedure," Tunnelling and Underground Space Technology, vol. 83, pp. 324-353, 2019.

[24] A. Sajjad, S. Kourosh, and H. M. Sayyed, "Developing intelligent classification models for rockburst prediction after recognizing significant predictor variables, section 2: designing classifiers," Tunnelling and Underground Space Technology, vol. 84, pp. 522-537, 2019.

[25] W. D. Ortlepp, "Note on fault-slip motion inferred from a study of micro-cataclastic particles from an underground shear rupture," Pure and Applied Geophysics PAGEOPH, vol. 139, no. 3-4, pp. 677-695, 1992.

[26] P. K. Kaiser, D. R. McCreath, and D. D. Tannant, Canadian Rockburst Support Handbook, Geomechanics Research Centre, Laurentian University, Sudbury, Canada, 1996.

[27] C. Srinivasan, S. K. Arora, and S. Benady, "Precursory monitoring of impending rockbursts in Kolar gold mines from microseismic emissions at deeper levels," International Journal of Rock Mechanics and Mining Sciences, vol. 36, no. 7, pp. 941-948, 1999.

[28] H. Sun, X. L. Liu, and J. B. Zhu, "Correlational fractal characterisation of stress and acoustic emission during coal and rock failure under multilevel dynamic loading," International Journal of Rock Mechanics and Mining Sciences, vol. 117, pp. 1-10, 2019.

[29] H. Sun, X. L. Liu, S. G. Zhang, and K. Nawnit, "Experimental investigation of acoustic emission and infrared radiation thermography of dynamic fracturing process of hard-rock pillar in extremely steep and thick coal seams," Engineering Fracture Mechanics, vol. 226, Article ID 106845, 2020.

[30] Q. Du, X. Liu, E. Wang, and S. Wang, "Strength reduction of coal pillar after $\mathrm{CO}_{2}$ sequestration in abandoned coal mines," Minerals, vol. 7, no. 2, p. 26, 2017.

[31] X. Liu, G. Han, E. Wang, S. Wang, and K. Nawnit, "Multiscale hierarchical analysis of rock mass and prediction of its mechanical and hydraulic properties," Journal of Rock Mechanics and Geotechnical Engineering, vol. 10, no. 4, pp. 694-702, 2018.

[32] T.-H. Ma, C.-A. Tang, S.-B. Tang et al., "Rockburst mechanism and prediction based on microseismic monitoring," International Journal of Rock Mechanics and Mining Sciences, vol. 110, pp. 177-188, 2018.

[33] C. Xu, X. Liu, E. Wang, Y. Zheng, and S. Wang, "Rockburst prediction and classification based on the ideal-point method of information theory," Tunnelling and Underground Space Technology, vol. 81, pp. 382-390, 2018.

[34] R. Markus, C. Gustau, S. Biorn et al., "Deep learning and process understanding for data-driven earth system science," Nature, vol. 566, no. 7743, pp. 195-203, 2019.

[35] Y. LeCun, Y. Bengio, and G. Hinton, "Deep learning," Nature, vol. 521, no. 7553, pp. 436-444, 2015.

[36] L. Rokach and O. Maimon, Data Mining with Decision Trees: Theory and Applications, World Scientific Pub Co. Inc., Hackensack, NJ, USA, 2008.

[37] J. R. Quinlan, "Induction of decision trees," Machine Learning, vol. 1, no. 1, pp. 81-106, 1986.

[38] B. Kamiński, M. Jakubczyk, and P. Szufel, "A framework for sensitivity analysis of decision trees," Central European
Journal of Operations Research, vol. 26, no. 1, pp. 135-159, 2017.

[39] B. Menze, B. Kelm, R. Masuch et al., "A comparison of random forest and its Gini importance with standard chemometric methods for the feature selection and classification of spectral data," BMC Bioinformatics, vol. 10, no. 1, p. 213, 2009.

[40] M. Ohtsu, "The history and development of acoustic emission in concrete engineering," Magazine of Concrete Research, vol. 48, no. 177, pp. 321-330, 1996.

[41] M. Cai and P. K. Kaiser, "Assessment of excavation damaged zone using a micromechanics model," Tunnelling and Underground Space Technology, vol. 20, no. 4, pp. 301-310, 2005.

[42] K. Ma, C. A. Tang, Z. Z. Liang, D. Y. Zhuang, and Q. B. Zhang, "Stability analysis and reinforcement evaluation of high-steep rock slope by microseismic monitoring," Engineering Geology, vol. 218, pp. 22-38, 2017.

[43] X.-T. Feng, Y. Yu, G.-L. Feng, Y.-X. Xiao, B.-R. Chen, and Q. Jiang, "Fractal behaviour of the microseismic energy associated with immediate rockbursts in deep, hard rock tunnels," Tunnelling and Underground Space Technology, vol. 51, pp. 98-107, 2016.

[44] T. H. Ma, C. A. Tang, L. X. Tang, W. D. Zhang, and L. Wang, "Rockburst characteristics and microseismic monitoring of deep-buried tunnels for Jinping II hydropower station," Tunnelling and Underground Space Technology, vol. 49, pp. 345-368, 2015.

[45] B. F. Russenes, "Analysis of rock spalling for tunnels in steep valley sides," M. Sc. thesis, Norwegian Institute of Technology, Trondheim, Department of Geology, Trondheim, Norway, 1974.

[46] G. Brauner, Rockburst in Coal Mines and Their Prevention, A. A. Balkema, Brookfield, Netherlands, 1994.

[47] Y. A. Tan, "Rockbursting characteristics and structural effects of rock mass," Science in China Series B, vol. 35, no. 8, pp. 981-990, 1992.

[48] W. Cai, L. Dou, G. Si, A. Cao, J. He, and S. Liu, “A principal component analysis/fuzzy comprehensive evaluation model for coal burst liability assessment," International Journal of Rock Mechanics and Mining Sciences, vol. 81, pp. 62-69, 2016. 